\title{
Mental Health, Poverty and Indigenous Psychology Research in East Nusa Tenggara-Indonesia: Methodological and ethical considerations ${ }^{\mathrm{a}}$

\author{
Yulius Yusak Ranimpi ${ }^{\mathrm{b}}$, Prof. Merv Hyde ${ }^{\mathrm{c}}$, Dr. Florin Oprescu ${ }^{\mathrm{d}}$
}

\begin{abstract}
In Indonesia, mental health issues have not recieved serious attention at the level of policy or practice. Moreover, concepts of mental health are contextualised within broader cultural, spiritual, socioeconomic and regional factors that alter perceptions of mental health and its relationship to poverty and other influences. This study proposes to explorethe relationship between poverty and mental health in a remote region of Indonesia. It is motivated by the lack of mental health services in the region and a lack of understanding of the psychological factors involved in realation to mental health in developing nations. To examine these issues, indigenous psychology, as opposed to Western or

Positivist Psychology, will be applied as a perspective,using phenomenology as a method. This paperdescribes the methodological and ethical considerations whichwill apply to this research.
\end{abstract}

Keywords

Mental health, indigenous psychology, phenomenology, methodological and ethical considerations

\section{Introduction}

Mental health in Indonesia has long been neglected. The effects of the environment (social, political, climatic, ecological, and economic) on the psychosocial well-being of a population are complex and multiple. In many parts of Indonesia, and over many decades, populations have endured deprivation and hardship, whether because of social conflict, poverty or natural disasters. A large number of people in Indonesia suffer from mental health afflictions, ranging from mild psychological distress to acute mental disorders. For the first time, in 2007, Indonesian Government conducted a national research in health sector which is included mental health issues. Based on respondents compliant and interviewer's observation, national prevalence for severe mental disorder is $0.5 \%$ and there are 7 provinces that have highest prevalence above the national prevalence average, which are Aceh, West Sumatera, South Sumatera, Bangka Belitung, Riau Islands, Jakarta, and West Nusa Tenggara. Based on Self-Reported Questionnaire, mental emotional disorder on people aged $\geq 15$ years old is $11.6 \%$ and there are 14 provinces that have highest prevalence above the national prevalence average, which are Aceh, West Sumatera, Riau Islands, Bangka Belitung, Jakarta, West Java, Central Java, East Java, West Nusa Tenggara, East Nusa Tenggara, Central Sulawesi, South Sulawesi, Gorontalo, and West Papua (Ministry of Health, 2008).

The discipline of psychology was developed in the Western world within largely positivist and individualist frameworks. Throughout the history of psychology, the theories and their proponent all came from the Americas and Europe. As Cohen (1999) suggests, indigenous perceptions of human behaviour not only differ from Western classifications of mental health, but some conditions that warrant special attention in Western contexts may have positive connotations in an indigenous society. From another perspective, the human rights of

\footnotetext{
This research is supported by Indonesia Directorate General of Higher Education (DIKTI) Scholarship 2013 (\#GL: 444/E4.4/K/2013)

${ }^{b}$ Ph.D student at University of the Susnhine Coast-Queensland-Australia and Lecturer at Faculty of HealthSciences; Satya Wacana Christian University Salatiga-Indonesia. Email: yulius.ranimpi@staff.uksw.edu; yry001@student.usc.edu.au

c University of the Sunshine Coast-Queensland-Australia

d University of the Sunshine Coast-Queensland-Australia
} 
indigenous peoples should be recognized because of their inherent dignity and because they make a significant contribution to the development and plurality of society (Cohen, 1999).

A common approach used to examine mental health issues and poverty is the paradigm of positivism. This approach presupposes social phenomena as being relatively exact and universal. The approach is problematic with many indigenous communities in developing countries, as it may not be relevant or applicable in health policy or understandable within the indigenous communities themselves.Therefore, from the perspective of indigenous psychology, it is relevant to examine the interrelationships among socio-cultural environments, poverty and mental health. In this approach, mental health can be considered as being deeply enmeshed within economic, social, cultural, spiritual and ethnographic contexts such as poverty, hunger and malnutrition, social change, violence and dislocation. Kim and Berry (1993) suggest that indigenous psychology questions the universality of existing psychological theories and attempts to discover psychological universals in social, cultural and ecological contexts. Indigenous psychology advocates examining knowledge, skills, and beliefs people have about themselves and how they function in their familial, social, cultural, and ecological context.As psychological and social phenomena, mental health and poverty will be the starting point for building theories, concepts, and methods to address the research questions. For example, there are some studies (Buckner, Beardslee, \& Bassuk, 2004; Fitzpatrick, Piko, Wright, \& LaGory, 2005) that have examined the relationship between mental health and poverty or other social phenomena.

The perspective of indigenous psychology has the capacity to refelect the diversities and differences found among communities in developing countries and better identify the conceptions of poverty and mental health and the relationships between them in an indigenous context and setting.

\section{Research location and setting}

This research projectwill be located at Binaus village, Soe District, East Nusa Tenggara Province-Indonesia. This village is a remote area and represents minimal natural and social conditions in East Nusa Tenggara province.

Based on data from East Nusa Tenggara Statistical Office (BPS NTT, 2013), the rate of poverty in this region was $20.4 \%$ of a total population of $4,776,485$ (12.2\% living in urban areas, $22.4 \%$ living in rural areas). This figure is far higher than the national average, which is $11.7 \%$ ( $8.6 \%$ living in urban areas, $14.7 \%$ living in rural areas). In accordance with this situation, other indicators that are related with poverty include school participation and the illiteracy rate (see Tables 1.1, 1.2 for details):

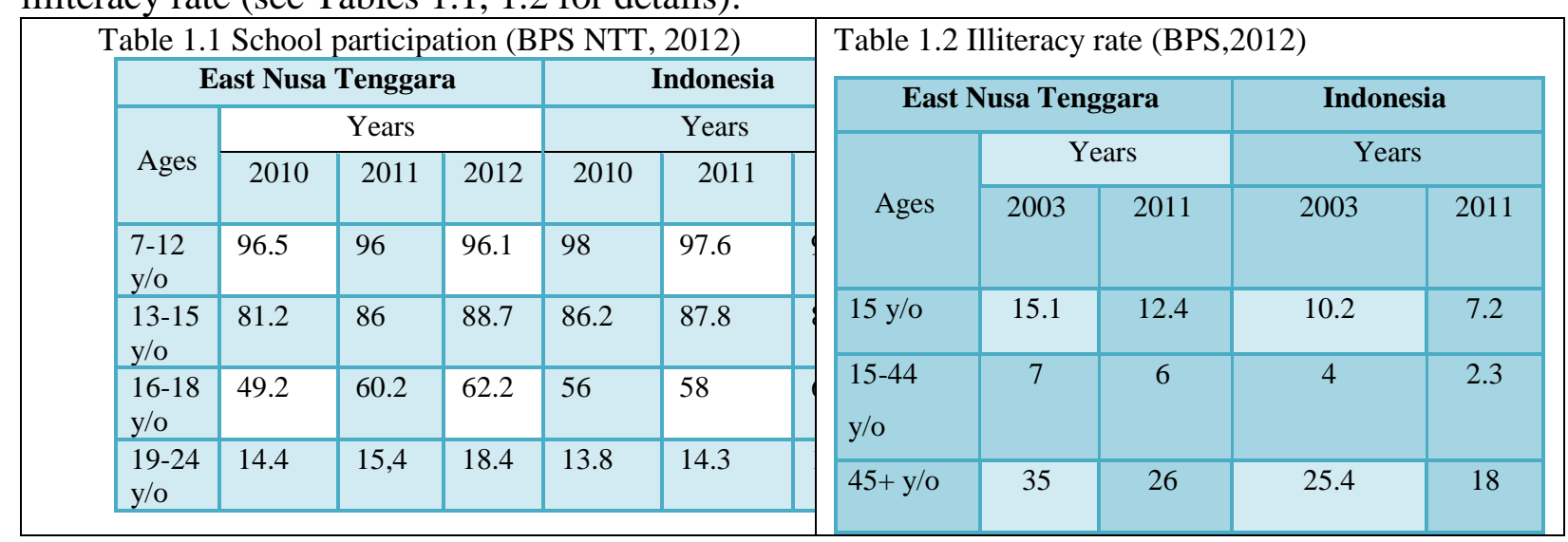


As Table 1.1shows there was anincrease ofschoolparticipationfor every age group from 2010 to 2012.However, this increase was limited, especially in the age groups of 16-18 years old and 19-24 years old.This outcome may be influenced by poverty, in that school-age children choose to seekwork (in their own region or outside the region).In 2012, from 2.1 million workers, there were 17.1 per cent of people aged 15-24 years who were eligibleto be in school. As an implication of the low rate of school participation, especially for those 15 years old and 15-44 years old, the rate of illiteracy in this group is still high with $12.4 \%$ and $6 \%$ respectively in 2011. These illiteracy rate in 2011 are still significantly higher than the national avarages (7.2\% and 2.3\%). The other relevant factor isreadiness to work.In 2012 the percentages of workers in NTT by level of education are: $66.3 \%$ not educated or having only completed elementary school, $11.9 \%$ having completed junior high school, $14.8 \%$ having completed senior high school, and only 7.1 having completed education from a university. In summary more than $70 \%$ of the workforces in NTT have low levels of education (BPS NTT, 2012).

On the other hand, public health data in NTT indicatea miserable condition, characterized by factors such as a lack of nutrition for babies $9.0 \%$ with a national average of $4.9 \%$, a lack of nutrition among adults $19.7 \%$ with a national average of $12.6 \%$ (Health Ministry, 2010). Added to this, a higher percentage of mental and emotional disorders canbe observed among Indonesian people aged over 15 years in this region, which is more than the national average (14.5\% compared with $11.6 \%$ )(Health Ministry, 2007).Especially for people under 15 years old, there are no recent data; the latest data is from 1995. In that year, based on a household health survey initiated by the Indonesian Health Department (Research and Development Unit), from among 1,000 household members there were 104 school-aged children who were reported as suffering from a mental health disorder.

Negative associations between level of poverty and incidence of mental health conditions in developing countries has been previously documented. Such research generally shows that low levels of income, education, assets and lower social class are correlated with higher probability of mental health problems (Lund et al, 2010). However, evidence about the nature and direction of any causal effect between the two measures remains limited in developing countries.

While some previous studies support the notion that there is a negative correlation between levels of poverty and mental health (Hanandita\&Tampubolon, 2014), more recent statictical analyses of the coincidence between poverty and mental health have not shown a consistently inverse relationship in developing contries (Tampubolon\&Hanandita, 2014). Where a correlation has been observed its is not clear whether the relationship is has causal features. Further, such statictical studies use conventional measures and concepts of mental health, as established in developed nations, and are not open to examining the potential for different conceptions of mental health among poor and remote communities. The study being conducted and reported here allows for new perspectives of the conceptions of mental health and poverty and the possible relationship between them.

\section{Rationale, question and objective of research}

In addition to the need to more fully understand the nature of the relationship, if any, between poverty and mental health, there is also a need to better position future research designs within the cultural and social lives of participants in poor and remote communities. For example, in whose conceptual paradigm is the research positioned - the communities or that 
of the researchers? Most previous studies have used quantitative approaches to analysis of existing statistical data framed within conventional Western models of pathology, sociology and psychology.

The study positions its research design within the paradigm of aindigenous psychology and to use a qualitative approach to eliciting the perspectives of the participants themselves about their conceptions of poverty and mental health and the nature of any relationship between these dimensions. Within such a research design ethical considerations are of critical importance.

\section{Methods}

This researchis qualitative in nature. It is concerned with the naturalistic description or interpretation of phenomena in terms of the meanings these have for the people experiencing them (Langdridge, 2007). Qualitative research is reflective, interpretive, descriptive, and seeks to describe and understand actual instances of human action and experience from the perspective of the participants who are living in a particular situation (Fischer, 2006). As cited by Ehrich (2003), Husserl believed the goal of phenomenological psychology was to apply the phenomenological method to psychological enquiry. Husserl referred to phenomenological psychology as an 'eidetic science', since the eidetic reduction 'provide[d] the means of access to the invariant essential structures of the total sphere of pure mental process' (in Ehrich, 2003).

In this research, an approach of descriptive phenomenology that is based on the Sheffield School (Ashworth, 2003) will be employed. This method builds on the Duquesne School, especially on Giorgi's work (Langdridge, 2007). The focus is, therefore, a description of the participant's lifeworld, as is the case with all descriptive phenomenology, but the analytical process also entails examination of seven structures or 'fractions' thought to be essential features of the lifeworld (Langdridge, 2007).

\section{Data collection}

Sampling and research participants. The method of sampling in this research will be a combination of maximum variation sampling and snowball sampling.Participants who have a common experience but who vary on as wide a variety of demographic characteristics as possible (Langdridge, 2007), such as age, gender, level of formal education and economic status, will be sought. To facilitate good communication, research participants need to speak the Indonesian language, or translator maybe considered if they cannot. The principle underpinning this approach to sampling is that with such variation, it should become possible (in the analytical stage) to ascertain those aspects of the experience that are invariant across perception (the essence(s) of the phenomenon) and those that vary across perception. Sample sizes are usually very small due to the timeconsuming nature of the analytical process (Langdridge, 2007).

Key informants, this research will involve some key informants, namely traditional leaders, religious leaders, the local government member, local researchers and academics, health workers, and nongovernment organization activists.

To collect the data, semi-structured interviewswill be used as the main tool.This type of interview is the basis for depth information probing. The construction of the interview covers topics, such as the local beliefs about human origin (human mythology or philosophy), 
people's belief (and experience) of health, mental health, poverty, in what particular circumstances they will claim to be a poor person or ill, how they see and state the relationship between mental health state and poverty, how they construct their capability to cope with those problems, and so on.

It is important to establish a good relationship with the research participants, so in the interview process there is no feeling of awkwardness and the participant is comfortable enough to give an answer or an explanation of their experience. Another consideration is the selection of time and place for the interview, i.e. a mutually agreed time when the research participants are comfortable and in quiet palce so they are not disturbed by the interview.

To maintain and keep the data safe, the researcher will use electronic recording equipment and also keep records manually. The main purpose of using equipment is that it will enable the easy transcription of data.

To understand the context of the people interviewed, observation is essential. In this case the research is participant observation which tends to take place in natural settings (work place,home, church), where the observer can be known as a researcher (overt) (Wllig, 2008).In some settings, observation note-taking, may be delayed until after observation, particularly where participation requires the researcher's full attention. Note-taking will then have to wait. The observations will then be recorded as soon as possible after they have been made, partly to counteract the possibility of forgetting but also because perceptions may change after period of reflection.

Theself-written/self-recording descriptionwill be used if the participants feel it is difficult to express their answers directly in a face to face interview. In essence, this involves the researcher providing the participants with some instructions asking them to produce a written document describing in as much detail as possible an experience of interest to the researcher (Langdridge, 2007). This technique is used on the condition that the research participants are individuals who find it "difficult" to express their thoughts or opinions in person. The data obtained will inform further interactions. Initial data describing an experience can be elicited using this method, and then a short time later (a week or two) a semi-structured interview can be conducted, designed to encourage participants to elaborate on and clarify the written material they have provided. The written component gives participants the opportunity to tell their own story, while the interview allows researchers to explore topics of particular interest (Langdridge, 2007).

\section{Data analysis}

Data obtained will be transcribed and then analysed using Giorgi's framework and also Ashworth's, whose, initial stages are the same(Langdridge, 2007). Briefly, here are three stages to a descriptive phenomenological analysis by Giorgi (1985; Giogi and Giorgi, 2003 as cited by Langdridge, 2007). The first stage requires the analyst to read (and probably re-read several times) the individual descriptions of participants' experience that is the focus of the analysis to grasp an overall sense of it.In the second stage the texts are broken down into smaller units of meaning, syetematically, in order to discern discrete meaning-units. The third stage involves assessing the meaning units for their psychological significance. Some units will have no particular psychological meaning and so will be ignored, while others will be psychologically meaningful. Multiple reading of the meaning units, reflecting and engaging in imaginative variation (a process oa approaching the phenomenon being experienced from different perpectives by imaginatively varying features of the phenomenon) are all ways of determining the psychological (or, indeed, sociological or educative) meaning of the discrete units identified in the previous step. At this point, Ashworth's approach different from Giorgis's by continue the analysis with seven fractions of lifeworld. This 
approachdescribeds by Ashworth based on Merleau-Ponty'sPhenomenology of perception (Ashworth, 2003; Langdridge, 2007) which areselfhood refers to that aspect of experience that might impact on a person's sense of agency, presence and voice. Here, selfhood is not something individual but rather something inextricably social or that which emerges between people in interaction. Sociality concerns the way in which a situation affects a person's relations with others, as all situations are intrinsically intersubjective. Embodiment relates to how the body features in experience, including consideration of sex, sexuality, disabilities, etc. Temporality refers to the way in which we are always living in time and how a person's sense of time might serve to underpin the experience being described. Spatiality concerns a person's understanding of space and place. Project is that aspects of a situation that relates to a person's ability to carry out activities that they have committed to and that they believe are central in their life. Finally, Discourse concerns the set of language terms (discourses) drawn on from the wider culture in order to describe an experience.

\section{Strategies to validate findings}

To enhance the quality of research and findings, several validation strategies suggested by Creswell (2007) will be employed:

a. Prolonged engagement and persistent observation in the field, including building trust with participants, learning the culture, and checking for misinformation that stems from distortions of participants' informantion introduced by the researcher.

b. Peer review or debriefing to provide an external check of the research processes much in the same spirit as interrater reliability in quantitative research. Lincoln and Guba (1985, as cited by Creswel, 2007), define the role of the peer debriefer as a "devil's advocate", an individual who keeps the researcher honest, asks hard questions about methods, meanings, and interpretations, and provides the researcher with the opportunity for catharsis by sympathetically listening to the researcher's feelings.

c. Member checking to solicits participants' views of the credibility of the findings and interpretations. This approach, writ large in most qualitative studies, involves taking data, analyses, interpretations, and conclusions back to the participants, so that they can judge the accuracy and credibility of the account. The analysisconsisting of description or themes, will be taken back to participants for their examination and they will be asked to provide alternative language, or "critical observations or interpretations" (Stake, 1995, as cited by Creswell, 2007). In addition to being checked by the research participants, this research report will also be checked by experts and practitioners associated with this research topic.

\section{Ethical considerations}

As a qualitative factor, particularly in phenomenologicalresearch that tries to seek perspectives on mental health and poverty issues in a remote area from participants with a different culture to the researcher,some ethical points must be onsidered.

The first step is to obtain permission from the local goverment or local community leader for that area of research. One advantage for the research team is that one works at Satya Wacana Christian University Salatiga, which already has a partnership agreement (MoU) with the local government, for this field of research, so that could be the legal entry point for askingcultural pemission to undertake this line of enquiry. To directly receive cultural approval ismore complex than obtaining legal permission. Thus, it is vital for the researcher to stay in the community for a reasonable period of time, i.e, 6 months in the current study. 
Following cultural approval, the situation will be more conducive to the data collection process, including finding and research participants. Research participants will be categorized into three major group: families, community leader/s, and religious leader/s, and further,participant categories will be determined based on sex (female and male), age (young, adult and elderly), education status (no schooling and unfinished primary school, finished primary school, finished junior high school), and main job (jobless, farmer, labour). Those categories will be obtained by interviews with thecommunity and religious leader/s as key informants. By identifying in this way, this research will be able to find the suitable sample of participants.

To protect participants' identity and to gain their personal approval and full participation, it is essential to provide a clear and understandable informed consent whereby participants need first to comprehend and second to agree voluntarily to the nature of their research and their role within it (Israel \& Hay, 2006). In most circumstances, researchers need to provide potential participants with information about the purpose, methods, demands, risks, inconveniences, discomforts and possible outcomes of the research, including whether and how results might be disseminated and researchers must invite participants to engage actively in the exchange of information (Faden and Beauchamp,1986 as cited by Israel \& Hay, 2006; Miller \& Bell, 2002). In general, participants' agreement to take part should be recorded, either by asking them to sign a form, return a survey, or give consent on audio- or video-tape (Israel \& Hay, 2006). In this research an explanation about this research and the kind of participation sought will be given, and probable risks and how to deal with them will be also will described. In this case participants will be asked to sign the informed consent form and return it after they fully understand this aspects of this research project.They will also be reminded about the chance to withdraw from this reserach with no explanation. If the participants are illiterate and cannot speak the Indonesian language, a significant person in their family or community will be asked to translate and explain the content of the informed consent and to try to get the agreement through a voice recorder. For young participants, parents will be asked to sign the informed consent on their behalf.As a legal document, the informed consent will be available in the Indonesian language.

In relation to protecting participants' identity, the value of confidentiality and anonymity are significant. In general, confidentiality, according to Canter et al (1994) as cited by Daniel and Kitchener (in Kitchener, 2000), means that non-public information about a person will not be disclosed by a third party without consent or special legal authorization. Confidentiality, therefore, is a commitment made by a professional, such as a lawyer, physician, or psychologist, to respective clients, research participants and others that private information will not be divulged without their consent. In other words, privacy is an individual right, whereas confidentiality involves private information that is divulged in a relationship between two or more people (Smith-Bell \& Winslade, 1994, cited by Daniel and Kitchener in Kitchener, 2000). For psychologists, confidentiality is central to the diverse roles and services provided to the public. From an ethical perspective, Kitchener (2000) cited that maintaining confidentiality is grounded in the principles of autonomy, fidelity, beneficence, and nonmaleficence. Respect for autonomy, or the right to self-governance (Beauchamp \& Childress, 1994, cited by Daniel and Kitchener in Kitchener, 2000), implies that individuals have the right to make decisions about those with whom they wish to share private information and those from whom they wish to withhold it. 
Without control over who has access to information about themselves, Bok (1983-1988) said that individuals could not protect private information or guard against dangerous disclosures (as cited by Daniel and Kitchener in Kitchener, 2000). Second, respecting the privacy of intimate human interactions and the personal secrets others share is at the core of human relationships, thus, the principle of fidelity adds further justification for keeping confidences. Third, when consumers or research participants share private information about themselves after a psychologist has extended a professional promise of confidentiality, a fiduciary relationship has been formed.

As a part of informed consent processes, it is important that researchers are explicit about all the elements of the confidentiality promise. It is simply not sufficient that the researcher promises to the respondent to keep the data confidential. First, there should be an explicit statement about the people who will have access to the data provided by a particular respondent; it should be clear who will be able to read and scrutinize the data provided. Second, the respondent should be informed about the plans for retaining the data, and for providing access to other researchers during that period. The respondent should have a clear and unambiguous understanding of those people who will see the information they will be asked to provide and they should be informed about the procedures to be used to try to ensure that the identities of respondents remain undisclosed (Oliver, 2003).

Another important consideration in this research is beneficence. At a micro level, this research is an attempt to give an answer to the problems in Indonesia, especially in mental health issues and their relation with poverty. Therefore, this research is designed with serious attention on minimizing the negative impact and maximizingbeneficial impact. The principal researcher is aware of the possibility of negative impacts experienced by the participants. To anticipate that and to optimize the beneficialaspects of this research, participants have the right to re-read, revise and improve the information given to the researcher, participants and community will be offered aempowerment training to establish their coping and social support strategies on mental health and poverty issues, and arrangements will be madesto establish an institutional network in case of emerging mental health problems requiring treatment from health workers when the researcher is not on-site.

\section{Conclusion}

In conclusion, this paper proposes a methodological and ethical framework in which the researcher can explore the conceptions of poverty and mental health within a poor and remote community and be able to reveal new insights that may influence existing theoretical and practical ways of understanding and responding to these challenges in such communities in Indonesia.Such theoretical and practical implications can benefit future research in similiar settings and paradigms. 


\section{References}

Ashworth, P. (2003). An approach to phenomenological psychology: The contigencies of the lifeworld. Journal of Phenomenological Psychology 34 (2),145-156.

BPS NTT.(2012). Ringkasan data ketenagakerjaan Provinsi Nusa Tenggara Timur tahun 2012. Kupang: BPS NTT.

BPS NTT.(2013). Nusa Tenggara Timur dalam angka. Kupang: BPS NTT.

Buckner, J. C., Beardslee, W. R., \& Bassuk, E. L. (2004). Exposure to violence and low income children's mental health: Direct, moderated, and mediated relations. American Journal of Orthopsychiatry, 74 (4), 413-423.

Cohen, A. (1999). The Mental Health of Indigenous People: an International Overview. Geneva: World Health Organization.

Creswell, J.W. (2007). Qualitative inquiry and research design: Choosing among five approaches. Second edition. London-New Delhi: Sage Publications.

Ehrich, L.C. (2003). Phenomenology: The quest for meaning. In Qualitative Educational Research In Action: Doing and reflecting. In T.A. O'Donoghue and K.F. Punch (Eds). London: RoutledgeFalmer.

Fischer, C.T. (2006). Qualitative Research methods for psychologists: Introduction through empirical studies.Burlington-San Diego-London: Academic press and Elsevier.

Fitzpatrick, K., Piko, B., Wright, D., \& LaGory, M. (2005).Depressive symptomatology, exposure to violence, and the role of social capital among African American adolescents. American Journal of Orthopsychiatry, 75(2), 262-274.

Hanandita, W., Tampubolon, G. (2014). Does poverty reduce mental health? An instrumental variable analysis. Social Science and Medicine, 113, 59-67.

Health Ministry. (2007). Report on result of basic health research (RISKESDAS). Jakarta: Indonesia Health Ministry.

Health Ministry. (2010). Report on result of national basic health research. Jakarta: Indonesia Health Ministry.

Israel, M., Hay, I. (2006). Research Ethics for Social Scientists: Between ethical conduct and regulatory compliance. London-Thousand Oaks-New Delhi: Sage Publications.

Kim, U., Berry, J. W. (1993). Indigenous Psychologies: Experience and Research in Cultural Context. Newbury Park, CA: SAGE Publications Ltd.

Kitchener, K.S. (2000). Foundations of Ethical Practice, Research, and Teaching in Psychology. New Jersey-London: Lawrence Erlbaum Associates, Inc. 
Langdridge, D. (2007). Phenomenological psychology: Theory, research and method. England: Pearson Education Limited.

Lund, et al., (2010). Poverty and common mental disorders in low and middle income countries: a systematic review. Social Science and Medicine, 71, 517-528.

Miller, T., Bell, L. (2002). Consenting to what? Issues of accsess, gate-keeping and 'informed' consent.In Ethics in qualitative research. M. Mauthner, M. Birch, J. Jessop \& T. Miller (Eds). London-Thousand Oaks-New Delhi: Sage Publications.

Oliver, P. (2003). The student's guide to research ethics. Philadelphia: Open University Press.

Tampubolon, G., Hanandita, W. (2014). Poverty and mental health in Indonesia. Social Science and Medicine, 106, 20-27.

Willig, C. (2008). Introducing Qualitative Research in Psychology, second edition. England: McGraw-Hill Ltd. 